\title{
Doença de Von Hippel-Lindau
}

\section{Von Hippel-Lindau disease}

A doença de Von Hippel-Lindau (VHL) é uma síndrome de neoplasias multisistémicas, de herança autossómica dominante (AD), com origem numa mutação no gene supressor tumoral VHL ${ }^{1}$. Aproximadamente $20 \%$ dos doentes com VHL apresentam mutações de novo não existindo uma história familiar positiva. A doença caracteriza-se predominantemente por hemangioblastomas cerebrais $(\mathrm{HC})$, retina e medula espinhal, feocromocitomas e paragangliomas, carcinoma de células renais e quistos viscerais (ex: renais e pancreáticos) ${ }^{1-4}$.

Na presença de história familiar positiva basta a identificação de uma lesão tumoral típica de VHL num familiar directo para estabelecer o diagnóstico de doença de VHL. No entanto, na ausência de história familiar, é necessária a presença de pelo menos 2 lesões tumorais típicas da doença (ex: 2 hemangioblastomas (HB) ou um $\mathrm{HB}$ e um tumor visceral) $)^{1,4}$.

Descreve-se o caso de um doente de 38 anos, oligofrénico, com história de cefaleias e tonturas com vários anos de evolução, que recorreu ao serviço de urgência por apresentar agravamento desses sintomas nos 15 dias precedentes. Trazia consigo uma tomografia computorizada cerebral (TC-CE) realizada a pedido do seu médico assistente que evidenciava múltiplas lesões ocupantes de espaço no pavimento e parede lateral do IV ventrículo condicionando hidrocefalia muito marcada com edema associado colocando a hipótese de metástases ou HC.

Foi internado para estudo tendo realizado ressonância magnética cerebral (RM) e Angiografia cerebral que mostraram lesões no IV ventrículo, a condicionar alargamento deste e efeito de massa sobre as estruturas adjacentes, ponte e região bulbo-medular e nos hemisférios cerebelosos, compatíveis com múltiplos HC. A RM do neuroeixo evidenciou ainda mais duas lesões (corpo de C6 e C7-D1) sem efeito de massa de relevo. Pela hipótese de VHL foi submetido a TC toraco-abdominal que revelou a presença de cistadenomas pancreáticos e hemangiomas hepáticos. Solicitou-se então 0 estudo genético para detecção do gene VHL que confirmou o diagnóstico.

Tendo em conta a transmissão genética AD da doença, solicitou-se a história clínica familiar do doente, no entanto, tratava-se de um jovem institucionalizado desde o nascimento e sem registos dos antecedentes médicos dos progenitores. 0 doente também não possuía descendentes conhecidos.

Após discussão do caso com Neurocirurgia, o doente foi submetido a ventriculostomia do III ventrículo por se ter considerado a remoção cirúrgica ou radioterapia do hemangioblastoma de maior dimensão como procedimentos de risco demasiado elevado.

Os HB são uma manifestação cardinal da doença de VHL surgindo como forma de apresentação em $40 \%$ dos casos e em $60-80 \%$ dos doentes no decurso da evolução da doença. Estas lesões são mais comuns no cerebelo, medula espinal e tronco cerebral ${ }^{1,4}$. Os HC apresentam-se tipicamente com sintomas sugestivos de hipertensão intracraneana ou ataxia do tronco ou membros e quando associados a lesões quisticas tornam-se sintomáticos mais precocemente ${ }^{4}$.

0 padrão imagiológico das lesões cerebrais e, sobretudo, o estudo genético para VHL mostraram-se de especial importância no estabelecimento do diagnóstico de VHL num doente sem história familiar positiva conhecida e sem outras manifestações típicas da doença.

Em doentes com VHL e HC assintomáticos, a literatura sugere apenas vigilância imagiológica. A intervenção terapêutica está indicada em doentes com sintomas progressivos sugerindo-se a ressecação cirúrgica nas lesões acessíveis ou radioterapia quando as lesões são inacessíveis ou com elevado risco de défices neurológicos ${ }^{4}$.

\section{Bibliografia}

1. Maher ER, Neumann HP, Richard S. von Hippel-Lindau disease: a clinical and scientific review. Eur J Hum Genet. 2011;19(6):617-23. doi:10.1038/ejhg.2010.175.

2. Neumann HP, Wiestler OD. Clustering of features and genetics of von Hippel-Lindau syndrome. Lancet. 1991;338(8761):258.

3. Chittiboina P, Lonser RR. Von Hippel-Lindau disease. Handb Clin Neurol. 2015;132:139-56. doi:10.1016/B978-0-444 62702-5.00010-X.

4. Lonser RR, Glenn GM, Walther M, Chew EY, Libutti SK, Linehan WM et al. von Hippel-Lindau disease. Lancet. 2003;361(9374):2059-67. doi:10.1016/S0140-6736(03)13643-4.

Diagnóstico:

\section{Múltiplos hemangioblastomas cerebrais na doença de Von Hippel-Lindau}

\author{
Margarida Carvalho ${ }^{1}$, Vítor Braz ${ }^{2}$ \\ ${ }^{1}$ Departamento de Medicina Interna, ${ }^{2}$ Hospital São João - Porto-Portugal
}

Figura 1. Hemangioblastoma no IV ventrículo - corte coronal.

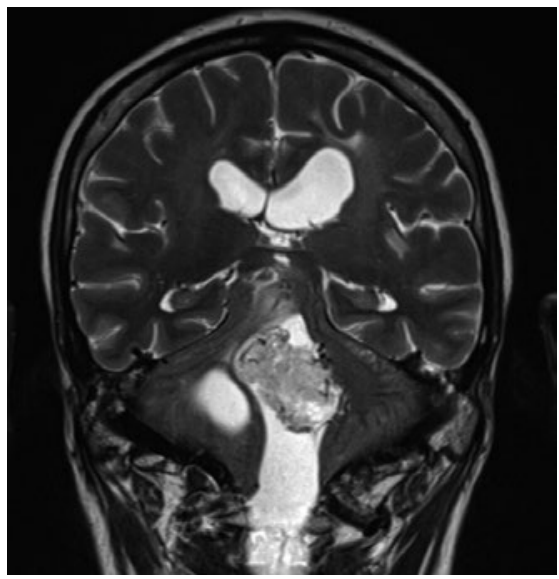

Figura 2.

Hemangioblastomas no cerebelo.

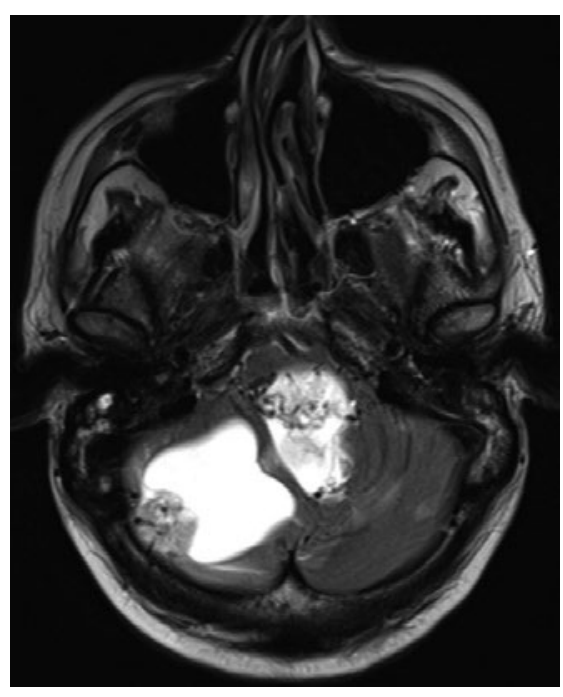

Figura 3.

Hemangioblastoma IV ventrículo.

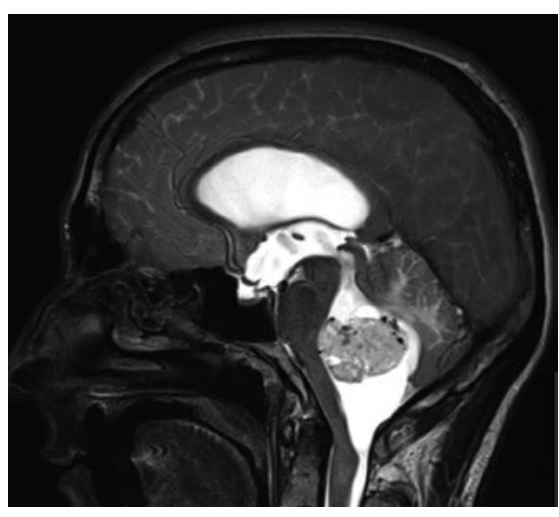

Correspondencia: amcocs@gmail.com

Como citar este artículo: Carvalho M, Braz V

Doença de Von Hippel-Lindau. Galicia Clin 2016; 77 (3): 145 Recibido: 29/01/16; Aceptado: 05/03/16 